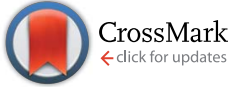

Cite this: RSC Adv., 2017, 7, 173

\title{
Tuning the photophysical properties of BODIPY dyes through extended aromatic pyrroles
}

\author{
Shawn Swavey, ${ }^{* a}$ John Quinn, ${ }^{a}$ Michael Coladipietro, ${ }^{a}$ Kegan G. Cox ${ }^{b}$ \\ and M. Kyle Brennaman ${ }^{\mathrm{b}}$
}

Three new BODIPY dyes have been synthesized by a two-step synthetic route. This expands the series to nine different BODIPY dyes by this method. Naphtha[1,2-c]pyrrole was combined with 1-pyrenecarboxaldehyde to give a symmetric dipyrrin followed by reaction with boron trifluoride to give a symmetric highly conjugated BODIPY dye. Expanding this synthetic route to a more conjugated pyrrole fluorantho[2,3-c]pyrrole was combined with 1-pyrenecarboxaldehyde followed by reaction with boron trifluoride to give the asymmetric BODIPY dye (9). Dyes with the more highly conjugated fluoranthopyrrole resulted in a bathochromic shift of ca. $50 \mathrm{~nm}$ in the electronic absorption and showed greater stability of the LUMO energy, as determined by electrochemical measurements, compared to their naphthapyrrole analogs. All of the dyes synthesized by this method display molar absorptivities greater than $100000 \mathrm{M}^{-1} \mathrm{~cm}^{-1}$ with photoluminescence quantum efficiencies of $0.8-1.0$. Excited state lifetimes of the dyes in dichloromethane are modest, ranging from 3.2 ns to 4.3 ns.

Received 4th November 2016 Accepted 29th November 2016

DOI: 10.1039/c6ra26331c

www.rsc.org/advances
Luminescence quantum efficiencies near unity were achieved with shorter-wavelength-absorbing BODIPY dyes; however, a significant decrease in quantum efficiency was observed for the biphenyl- and benzothieno-fused BODIPY dyes, 0.51 and 0.05 respectively. In addition to lower quantum efficiencies, the synthetic route to these fused BODIPY dyes requires multiple synthetic steps, harsh chemicals, and expensive catalysts. Rurack $e t$ al. has achieved luminescence quantum efficiencies near unity with absorption wavelengths between $621 \mathrm{~nm}$ and $642 \mathrm{~nm}$ from phenanthrene-fused BODIPY dyes with various mesosubstituents. ${ }^{25}$

We have recently described a two-step route toward BODIPY dyes $^{26}$ in which formation of the dipyrrin was accomplished in the absence of solvent. Using naphthyl-pyrrole and a variety of aromatic aldehydes, a series of new BODIPY dyes were generated with long-wavelength absorption properties ranging from ca. $580 \mathrm{~nm}$ to $620 \mathrm{~nm}$ and near unity quantum efficiencies. It was argued that by judicious choice of aromatic aldehyde, i.e. sterically hindered versus non-sterically hindered, the BODIPY dyes generated would be either asymmetric or symmetric respectively, Scheme 1 . To continue this study in an attempt to advance this new synthetic route as well as shift light absorption closer to the NIR, herein we report new BODIPY dyes based on fluoranthene pyrroles, Scheme 1 (framed).

\section{Experimental}

All chemicals were reagent grade and used without further purification. Naphtha[1,2-c]pyrrole, ${ }^{27}$ fluorantho[2,3-c]pyrrole ${ }^{28}$ and BODIPY dyes 1-6 (ref. 26) were synthesized as previously 

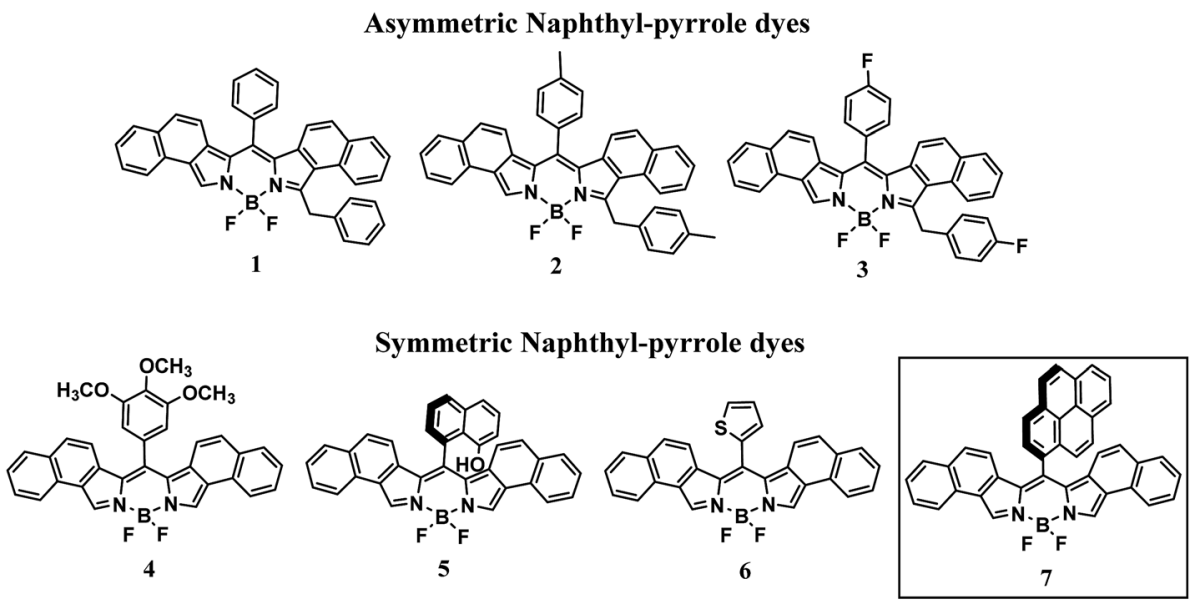

Fluorantho-pyrrole dyes
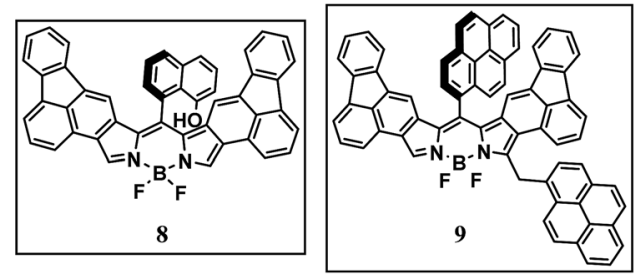

Scheme 1 Molecular structures of BODIPY dyes.

described. Chromatography was performed on a Teledyne Combiflash $R_{\mathrm{f}}+$ equipped with UV detection. High resolution mass spectral analysis was performed at the Mass Spectrometry and Proteomics facility at the Ohio State University. Elemental analysis was performed at Atlantic Microlabs Inc. Norcross, Georgia. ${ }^{1} \mathrm{H}$ NMR spectra were recorded on a Bruker $300 \mathrm{MHz}$ NMR spectrophotometer at $298 \mathrm{~K}$. Electronic absorption spectra were recorded at room temperature using an HP8453 photodiode array spectrophotometer with $2 \mathrm{~nm}$ resolution. All spectra were recorded at $298 \mathrm{~K}$. Room temperature luminescence spectra in a $1 \mathrm{~cm}$ quartz spectrophotometer fluorescence cell (Starna) in DCM were run on a Cary Eclipse fluorescence spectrophotometer. Cyclic voltammograms were recorded under a nitrogen atmosphere using a one-compartment, three electrode cell, CH-Instruments, equipped with a platinum wire auxiliary electrode. The working electrode was a $2.0 \mathrm{~mm}$ diameter glassy carbon disk from CH-Instruments, which was polished first using $0.30 \mu \mathrm{m}$ followed by $0.05 \mu \mathrm{m}$ alumina polish (Buehler) and then sonicated for $10 \mathrm{~s}$ prior to use. Potentials were referenced to a $\mathrm{Ag} / \mathrm{Ag}^{+}$non-aqueous electrode with ferrocene as an internal standard, CH-Instruments. The supporting electrolyte was $0.1 \mathrm{M}$ tetrabutylammonium hexafluorophosphate $\left(\mathrm{Bu}_{4} \mathrm{NPF}_{6}\right)$ and the measurements were made in dry DCM. Luminescence quantum yields were determined at room temperature in HPLC-grade DCM relative to Rhodamine 6G as the reference $(\phi=0.95$, in ethanol $) .{ }^{29}$ The quantum yields were obtained using the following equation:

$$
\phi_{\mathrm{s}}=\phi_{\mathrm{r}}\left[A_{\mathrm{r}} \eta_{\mathrm{s}}^{2} D_{\mathrm{s}} / A_{\mathrm{s}} \eta_{\mathrm{r}}^{2} D_{\mathrm{r}}\right]
$$

where $\mathrm{s}$ and $\mathrm{r}$ refer to the sample and reference, respectively, $A$ is the absorbance at the excitation wavelength, $\eta$ is the average refractive index of the solution, and $D$ is the integrated area under the emission spectrum.

\section{Time-resolved emission measurements}

Excited-state lifetimes were measured by the time-correlated single photon counting (TCSPC) technique implemented by using an Edinburgh Instruments FLS920 photoluminescence spectrophotometer. The FLS920 was outfitted with a Hamamatsu 2658P photomultiplier tube (PMT) mounted in a PMT housing cooled to $-22{ }^{\circ} \mathrm{C}$. Laser excitation was provided by a $484 \mathrm{~nm}$ diode laser (Edinburgh Instruments EPL-485, 93 ps FWHM pulse width, $2 \mathrm{~mm}$ beam diameter) operated at $20 \mathrm{MHz}$. Time-resolved emission for compounds 1-9 was monitored at $608,612,612,612,610,620,605,650$ and $650 \mathrm{~nm}$, respectively with a bandwidth of 5-10 nm. A $515 \mathrm{~nm}$ long-pass filter was placed before the entrance of the emission monochromator to remove laser scatter. Methylene chloride solutions of each compound were prepared with maximum visible absorbance values less than 0.2 OD. For each compound, at least two measurements were performed using air-saturated solutions at $22 \pm 2{ }^{\circ} \mathrm{C}$. Each transient decay was recorded on a $50 \mathrm{~ns}$ time range (12.2 ps per channel) to achieve 10000 peak counts. An instrument response function (IRF), with FWHM of $1.32 \mathrm{ns,}$ was obtained by tuning the monochromator to $484 \mathrm{~nm}$ and collecting the laser light scattered by an aqueous Ludox solution. Emission decays were treated in Edinburgh L900 software (v7.1.1) with a reconvolution fit incorporating the Ludox-based IRF. 


\section{General synthetic procedure}

To a $25 \mathrm{~mL}$ round bottom flask $50.0 \mathrm{mg}(0.30 \mathrm{mmol})$ of naphtha $[1,2-c]$ pyrrole or $(0.21 \mathrm{mmol})$ of fluorantho[2,3-c]pyrrole and a molar equivalent of the appropriate aldehyde were combined. Approximately $1 \mathrm{~mL}$ of dichloromethane (other solvents i.e. methanol, acetone, chloroform also work) was added to give a homogenous solution. The solvent was then removed under reduced pressure and the flask was placed in a warm water bath preset at $70{ }^{\circ} \mathrm{C}$ for $15 \mathrm{~min}$. Temperatures were increased until the reactant mixture turned to a purple paste. In the case of the fluorantho[2,3-c]pyrrole reactions, the mixture was placed in an oven and heated to $140{ }^{\circ} \mathrm{C}$. The resulting purple paste was chromatographed on silica gel using DCM (to remove any polymers formed) collecting the first deep red band. The solvent was removed under reduced pressure and the flask was degassed with nitrogen. Approximately $4 \mathrm{~mL}$ of dry DCM was added followed by $100 \mu \mathrm{L}$ of triethylamine and then $200 \mu \mathrm{L}$ boron trifluoride etherate. The solution was stirred at room temperature under nitrogen overnight. The reaction mixture was washed with distilled water, dried over magnesium sulfate and chromatographed on silica gel using 90/10 chloroform/hexanes as eluent. The first band was collected and the solvent removed.

7. Yield $11 \mathrm{mg}(12 \%) \mathrm{HRMS}$ calcd for $\mathrm{C}_{41} \mathrm{H}_{23} \mathrm{~N}_{2} \mathrm{BF}_{2}\left[\mathrm{M}^{+}\right]$ 592.19223 found 592.19156. ${ }^{1} \mathrm{H} \mathrm{NMR}\left(\mathrm{CDCl}_{3}\right): \delta \mathrm{ppm} 7.02(\mathrm{~d}, J=$ $9.0 \mathrm{~Hz}, 1 \mathrm{H}), 7.44-7.36(\mathrm{~m}, 2 \mathrm{H}), 7.57(\mathrm{dt}, J=9.3,5.8 \mathrm{~Hz}), 7.95(\mathrm{~d}, J$ $=9.2 \mathrm{~Hz}, 2 \mathrm{H}), 8.14-8.06(\mathrm{~m}, 3 \mathrm{H}), 8.24-8.16(\mathrm{~m}, 3 \mathrm{H}), 8.26(\mathrm{~s}, 1 \mathrm{H})$, $8.38-8.28(\mathrm{~m}, 5 \mathrm{H}), 8.52-8.42(\mathrm{~m}, 2 \mathrm{H}), 8.96(\mathrm{br} \mathrm{s}, 1 \mathrm{H}), 9.45(\mathrm{~d}, J=$ $9.45 \mathrm{~Hz}, 1 \mathrm{H})$.

8. Yield $9.6 \mathrm{mg}(14 \%)$ HRMS calcd for $\mathrm{C}_{47} \mathrm{H}_{25} \mathrm{~N}_{2} \mathrm{OBF}_{2}\left[\mathrm{M}^{+}\right]$ 682.20280 found 682.20200. Elemental analysis calculated for $\mathrm{C}_{40} \mathrm{H}_{25} \mathrm{~N}_{2} \mathrm{OBF}_{2} \cdot \mathrm{CHCl}_{3} \cdot 0.5 \mathrm{C}_{6} \mathrm{H}_{12}: \mathrm{C}, 72.57 ; \mathrm{H}, 3.82 ; \mathrm{N}, 3.32$; found, C, 72.15; H, 4.10; N, 3.57.

9. Yield $22 \mathrm{mg}(22 \%)$. HRMS calcd for $\mathrm{C}_{70} \mathrm{H}_{37} \mathrm{~N}_{2} \mathrm{BF}_{2}\left[\mathrm{M}^{+}\right]$ 954.30178, found 954.30378. Elemental analysis calculated for $\mathrm{C}_{70} \mathrm{H}_{37} \mathrm{~N}_{2} \mathrm{BF}_{2} \cdot 0.5 \mathrm{CHCl}_{3} \cdot 0.5 \mathrm{C}_{6} \mathrm{H}_{12}: \mathrm{C}, 83.55 ; \mathrm{H}, 4.15 ; \mathrm{N}, 2.65$; found, C, 83.31; H, 4.33; N, 2.66.

\section{Results and discussion}

\section{Synthesis}

In light of the recent report on the two-step synthetic route of highly conjugated BODIPY dyes ${ }^{26}$ we have attempted to extend this synthetic route. By heating naphtha[1,2-c]pyrrole and 1-pyrenecarboxaldehyde at $80{ }^{\circ} \mathrm{C}$ for $15 \mathrm{~min}$ followed by chromatography on silica gel, the red dipyrrin was obtained. The dipyrrin was converted to the BODIPY dye 7 (Scheme 2) by reaction with boron trifluoride in the presence of triethylamine and dry DCM as previously described. After workup and purification, 7 was obtained as a golden solid. Characterization by high resolution mass spectrometry and ${ }^{1} \mathrm{H}$ NMR confirmed the structure.

To further extend this procedure to more highly conjugated pyrroles, the readily available fluorantho[2,3-c]pyrrole was chosen. ${ }^{28}$ To obtain the dipyrrins based on this pyrrole; however, required heating at $140{ }^{\circ} \mathrm{C}$, considerably higher than the napthapyrrole based dipyrrins. After purification, the dipyrrins were converted to the BODIPY dyes $\mathbf{8}$ and $\mathbf{9}$ as previously described,
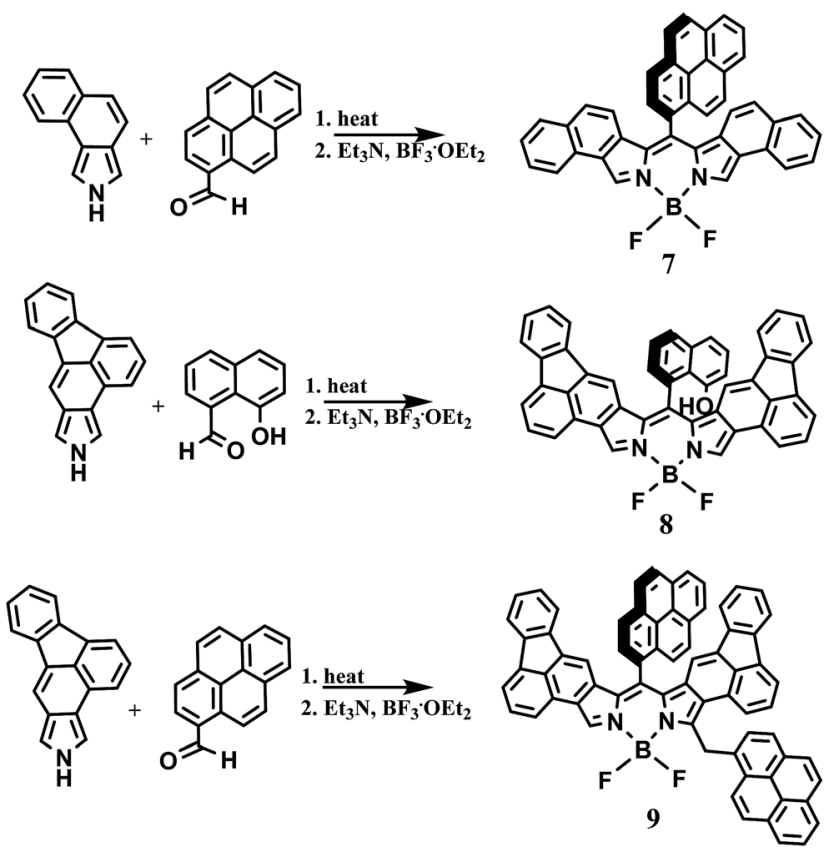

Scheme 2 Synthetic route of BODIPY dyes.

Scheme 2. Due to their complex proton NMR spectra, these dyes were characterized by high-resolution mass spectrometry and their purity determined by elemental analysis.

For naphtha[1,2-c]pyrrole, it was suggested that the steric bulk of the aldehyde determined the symmetry of the dipyrrin with the symmetric dipyrrin favored by highly substituted aldehydes. This does not seem to be the case with the fluorantho[2,3c]pyrrole. This is evidenced by the formation of the symmetric BODIPY dye $\mathbf{8}$ while the bulkier 1-pyrenecarboxaldehyde favors the asymmetric BODIPY dye 9. In addition, attempts to form BODIPY dyes from 3,4,5-trimethoxybenzaldehyde and 2-thiophenecarboxaldehyde, for comparison with our earlier study, resulted in only trace amounts of the desired products.

\section{Spectroscopic properties}

Electronic absorption and emission spectroscopy was performed for 7-9 in dry DCM at room temperature, Table 1 and

Table 1 Photophysical and electrochemical data for BODIPYs 1-9

\begin{tabular}{llllllll}
\hline Dyes & $\begin{array}{l}\lambda_{\mathrm{abs}} \\
(\mathrm{nm})\end{array}$ & $\begin{array}{l}\lambda_{\mathrm{em}} \\
(\mathrm{nm})\end{array}$ & $\begin{array}{l}\varepsilon, \mathrm{M}^{-1} \\
\mathrm{~cm}^{-1}\end{array}$ & $\begin{array}{l}\tau \\
(\mathrm{ns})\end{array}$ & $\phi^{a}$ & $\begin{array}{l}\text { LUMO } \\
(\mathrm{eV})\end{array}$ & $\begin{array}{l}\text { HOMO } \\
(\mathrm{eV})\end{array}$ \\
\hline $\mathbf{1}$ & 600 & 608 & 107000 & 4.2 & 1.0 & -3.6 & -5.3 \\
$\mathbf{2}$ & 600 & 612 & 152000 & 4.3 & 0.8 & -3.5 & -5.3 \\
$\mathbf{3}$ & 602 & 612 & 140000 & 4.0 & 1.0 & -3.5 & -5.3 \\
$\mathbf{4}$ & 596 & 604 & 158000 & 4.1 & 0.9 & -3.6 & -5.4 \\
$\mathbf{5}$ & 603 & 612 & 176000 & 4.2 & 1.0 & -3.7 & -5.4 \\
$\mathbf{6}$ & 612 & 619 & 194000 & 3.2 & 0.5 & -3.8 & -5.4 \\
7 & 599 & 613 & 138000 & 4.0 & 1.0 & -3.7 & -5.4 \\
$\mathbf{8}$ & 642 & 654 & 110000 & 3.5 & 0.8 & -4.0 & -5.4 \\
$\mathbf{9}$ & 645 & 657 & 124000 & 3.5 & 0.8 & -3.9 & -5.4
\end{tabular}

${ }^{a}$ Fluorescence quantum yields were obtained using Rhodamine $6 \mathrm{G}$ as a reference $\left(\phi=0.94\right.$ in ethanol). ${ }^{29}$ 
Fig. 1-3. BODIPY 5, from our previous study, was included for comparison. Fig. 1A illustrates the electronic absorption spectra of 5 and 8. In general, electronic excitations of BODIPY dyes are the result of HOMO to LUMO transitions localized on the dipyrrin core. ${ }^{\mathbf{1}}$ Both $\mathbf{5}$ and $\mathbf{8}$ exhibit sharp electronic absorption features, with the maximum absorption of 5 at $596 \mathrm{~nm}(\varepsilon=$ $\left.158000 \mathrm{M}^{-1} \mathrm{~cm}^{-1}\right)$ and of 8 at $642 \mathrm{~nm}\left(\varepsilon=110000 \mathrm{M}^{-1} \mathrm{~cm}^{-1}\right)$. The more highly conjugated BODIPY dye 8 shows a bathochromic shift of $46 \mathrm{~nm}$ compared to 5 .

The emission spectra of 5 and $\mathbf{8}$ are illustrated in Fig. 1B. The emission peak for 5 appears at $604 \mathrm{~nm}$ with a Stokes shift of $223 \mathrm{~cm}^{-1}$. The emission peak for 8 appears at $654 \mathrm{~nm}$ with a slightly larger Stokes shift of $285 \mathrm{~cm}^{-1}$. The luminescence quantum efficiency for 5 was determined previously to be $0.9 .^{26}$ Typically BODIPY dyes with emission maxima greater than $600 \mathrm{~nm}$ exhibit quantum efficiencies well below unity. Notably, the quantum efficiency of $\mathbf{8}$ is 0.8 , considerably higher than that observed for similar dyes with emission also peaking near $650 \mathrm{~nm}^{1}$

Normalized electronic absorption spectra of BODIPY dyes 7 and 9 are illustrated in Fig. 2A. Despite their structural differences with 7 symmetric and 9 asymmetric, both exhibit intense absorption peaks at wavelengths shorter than $400 \mathrm{~nm}$ indicative of the pyrene moieties. It is noteworthy that $\mathbf{9}$, which contains an extra pyrene arm compared to 7, displays similar but more intense absorption within this region of the spectrum. Similar to the other BODIPY dyes, both 7 and 9 display sharp, intense, absorption bands with absorption peaks of $599 \mathrm{~nm}(\varepsilon=$ $\left.138000 \mathrm{M}^{-1} \mathrm{~cm}^{-1}\right)$ for 7 and $645 \mathrm{~nm}\left(\varepsilon=124000 \mathrm{M}^{-1} \mathrm{~cm}^{-1}\right)$ for 9. This represents a $46 \mathrm{~nm}$ bathochromic shift for the more conjugated pyrrole, Fig. $2 \mathrm{~A}$ and Table 1. Emission of 7 is observed with a maximum at $613 \mathrm{~nm}$ with a Stokes shift of 381 $\mathrm{cm}^{-1}$, Fig. 2B. Dye 9 displays an emission peak at $657 \mathrm{~nm}$ with a Stokes shift of $283 \mathrm{~cm}^{-1}$, Fig. 2B. Luminescence quantum efficiencies for both 7 and $\mathbf{9}$ are at or near unity, Table 1 .

It has been previously established that due to a nearorthogonal arrangement between the BODIPY core and its meso-substituent, there is typically no overlap of the $\pi$-electron clouds. ${ }^{30}$ Indeed bulky meso-substituents limited by their size to freely rotate allow for extended lifetimes of the excited dyes by eliminating non-radiative decay mechanisms. ${ }^{31}$ Lifetime measurements of dyes 1-9 in DCM range from $3.2 \mathrm{~ns}$ to $4.3 \mathrm{~ns}$ suggesting the ability for non-radiative deactivation via some rotation at the meso positions. Surprisingly, dyes 8 and 9 exhibit the shortest lifetimes even though, structurally, they represent the most resistance to free rotation at the meso position. This
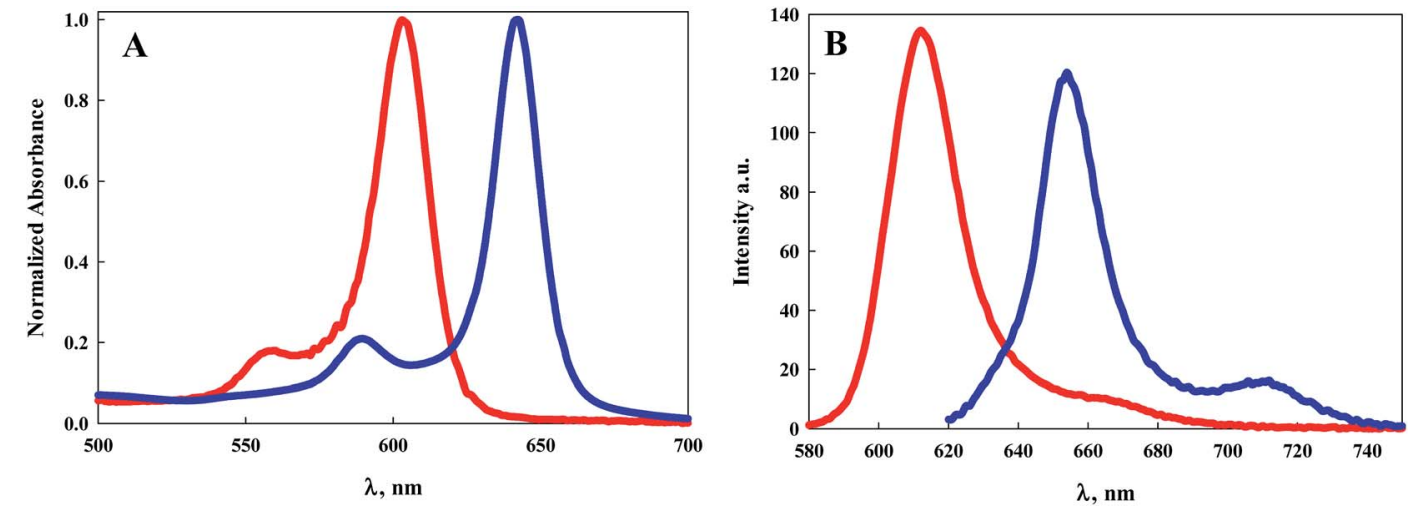

Fig. 1 (A) Electronic absorption spectra of 5 (red line) and 8 (blue line) in DCM; (B) emission spectra of 5 (red line) and 8 (blue line) when excited at their maximum absorption wavelength.
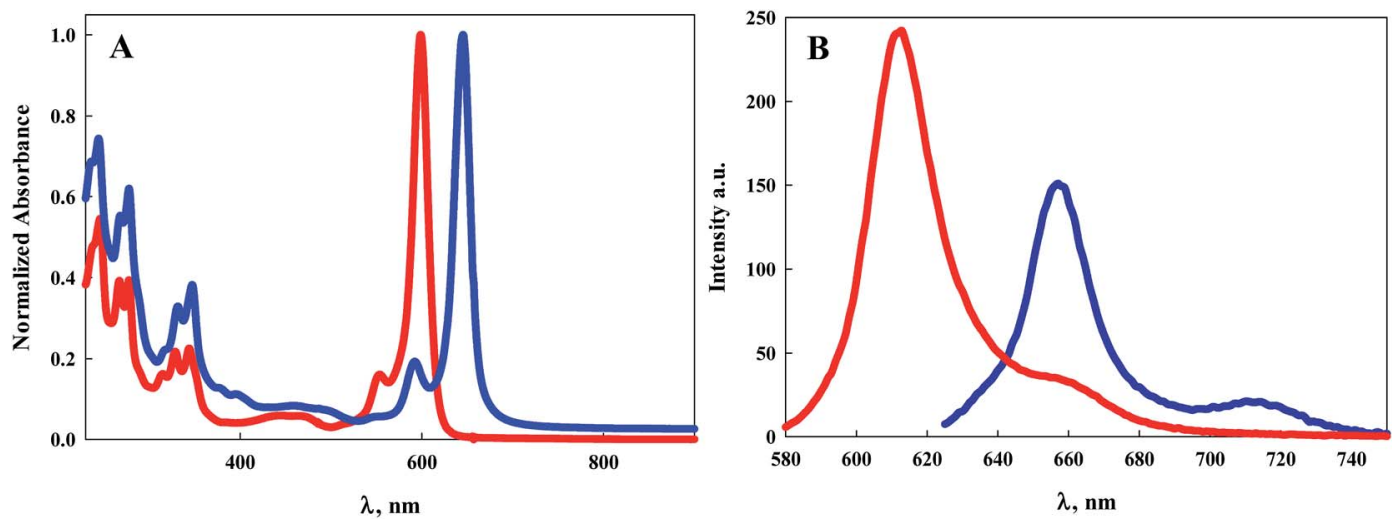

Fig. 2 (A) Electronic absorption spectra of 7 (red line) and 9 (blue line) in DCM; (B) emission spectra of 7 (red line) and 9 (blue line) when excited at their maximum absorption wavelength. 


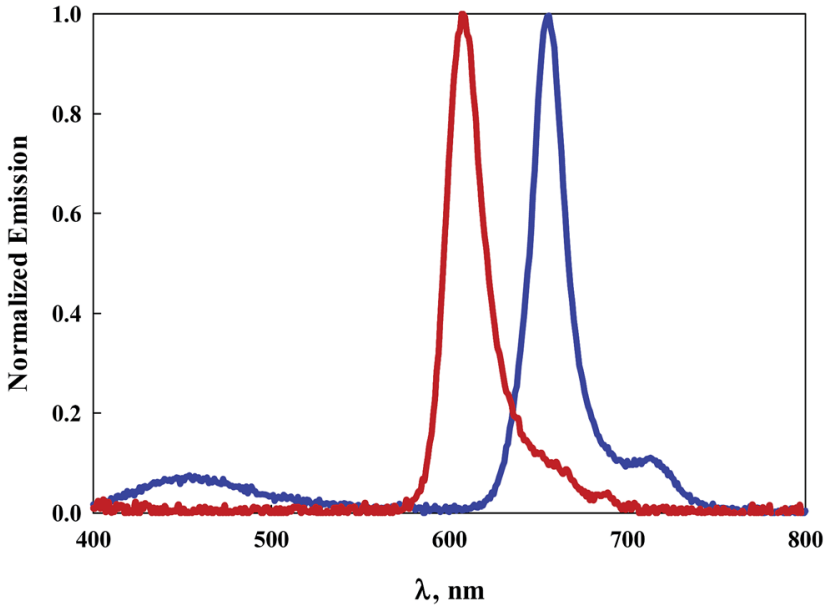

Fig. 3 Emission spectra of 7 (red line) and 9 (blue line) in DCM upon excitation at $344 \mathrm{~nm}$.

suggests that another mechanism for non-radiative deactivation is likely responsible for the shorter excited-state lifetimes. Of the dyes in this study, only the pyrene-substituted BODIPY compounds 7 and 9 display significant absorption in the UV region. For both 7 and $\mathbf{9}$, photoexcitation of the pyrene substituents at $344 \mathrm{~nm}$ results in emission peaking at $608 \mathrm{~nm}$ and $656 \mathrm{~nm}$ respectively, Fig. 3. A small emission peak is observed for the asymmetric, more highly conjugated dye 9 at $\sim 450 \mathrm{~nm}$ associated with the pyrene moiety. The observation that excitation of the pyrene generates emission from the BODIPY core suggests either a through-bond or through-space intramolecular excitation energy transfer process. ${ }^{30}$

\section{Electrochemical properties}

Cyclic voltammetry experiments were performed for 7-9 in DCM with TBAPF $_{6}$ as the supporting electrolyte. A one compartment three electrode cell was employed with a platinum wire auxiliary electrode and glassy carbon working electrode. The cell was equipped with a non-aqueous $\mathrm{Ag}^{+}$reference electrode and ferrocene as the internal standard. All experiments were performed at room temperature under a nitrogen atmosphere.

Scanning in the anodic direction, a quasi-reversible redox couple is observed for the BODIPY dye 7 with $E_{1 / 2}=0.68 \mathrm{~V}(\Delta E=$ $120 \mathrm{mV}$ ), Fig. 4A.

A reversible couple with $E_{1 / 2}=-1.23 \mathrm{~V}(\Delta E=60 \mathrm{mV})$ is revealed upon scanning in the cathodic direction. The cyclic voltammograms of the more conjugated BODIPY dyes 8 and $\mathbf{9}$ are less well defined, though redox activity is observed. In the case of $\mathbf{8}$, a broad, irreversible oxidation is observed in the anodic region of the voltammogram with a peak potential of $0.77 \mathrm{~V}$. When scanned in the cathodic direction, two irreversible reductions with peak potentials of $-1.03 \mathrm{~V}$ and $-1.43 \mathrm{~V}$ are observed, Fig. 4B. For 9, Fig. 4B, an irreversible oxidation with peak potential of $0.75 \mathrm{~V}$ is followed by a quasi-reversible redox couple in the cathodic region with $E_{1 / 2}=-1.06 \mathrm{~V}(\Delta E=70 \mathrm{mV})$. Scanning further in the cathodic direction reveals two irreversible reduction waves with peak potentials of $-1.45 \mathrm{~V}$ and $-1.67 \mathrm{~V}$.

From the onset of the oxidation and reduction waves, the HOMO and LUMO energies can be estimated. ${ }^{32}$ Scheme 3 depicts a Jablonski diagram of these energies for the BODIPY dyes of Scheme 1.

It has been established that coordination of the $\mathrm{BF}_{2}$ moiety to the dipyrrin serves to bring the $\pi$-orbitals of the dipyrrin into alignment, resulting in a sharper, more intense, bathochromically shifted electronic transition. ${ }^{1}$ Yet, theoretical calculations indicate that neither the HOMO nor LUMO electron density is located on the boron, but instead resides on the dipyrrin core. ${ }^{33}$ It is reasonable to assume then that any shifts in energy of the electronic transition of the BODIPY dyes is related to the pyrrole or the meso-substituent of the dipyrrin. From the Jablonski diagram of Scheme 3, it appears that with the naphtha[1,2-c] pyrrole-based dyes, the HOMO energy is unaffected by the composition of the meso-substituent. Despite this, the symmetric dyes show greater stabilization of the HOMO energy compared to the asymmetric dyes. In the case of the fluorantho $[2,3-c]$ pyrrole-based dyes, the HOMO energy is the same as that for the symmetric naphtha[1,2-c]pyrrole dyes and independent of the symmetry of the dye.
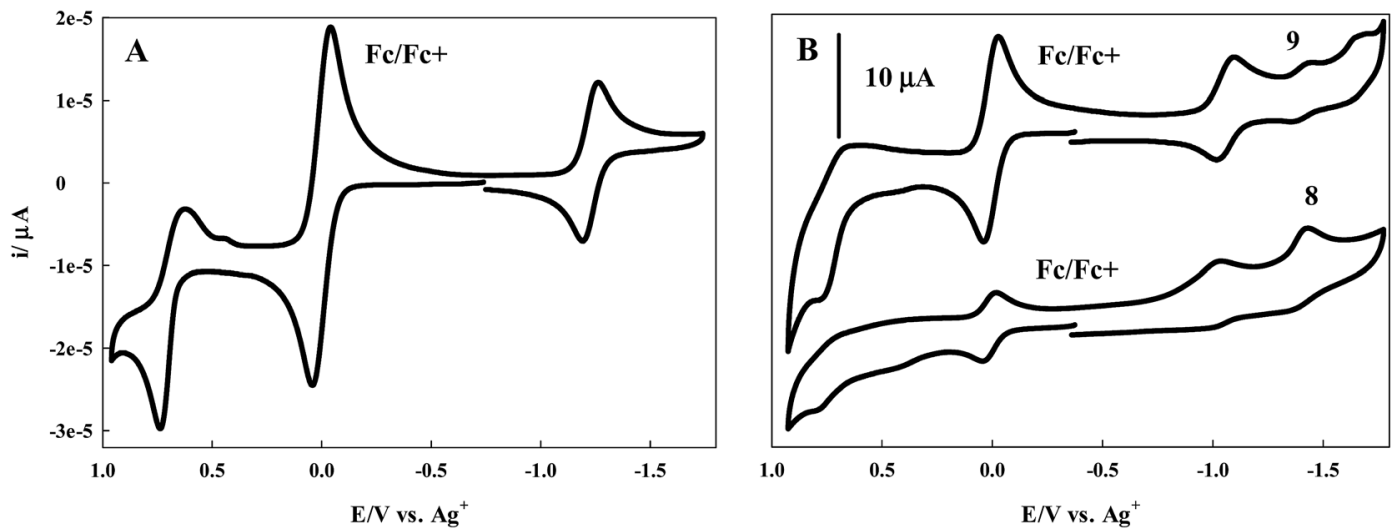

Fig. 4 (A) Cyclic voltammogram of 7 in DCM, (B) CV of 8 and 9 in DCM containing 0.1 M TBAPF 6 as the supporting electrolyte at room temperature, a glassy carbon working electrode, platinum wire auxilliary, $\mathrm{Ag} / \mathrm{Ag}^{+}$reference electrode, and ferrocene as internal standard. Scan rate $=100 \mathrm{mV} \mathrm{s}^{-1}$. 


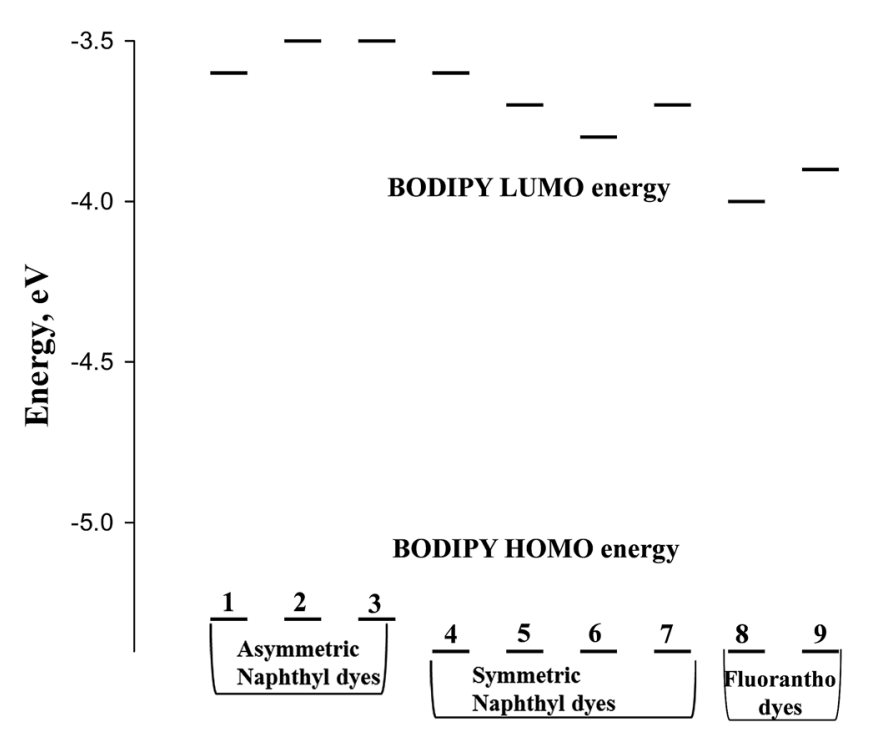

Scheme 3 Jablonski diagram for the BODIPY dyes illustrated in Scheme 1.

It is well established that meso-substituents of BODIPY dyes are typically orthogonal to the BODIPY core thereby preventing overlap of the $\pi$-cloud associated with the BODIPY core and the $\pi$-cloud of the aromatic meso-substituent. Theoretical studies have indicated that electron-withdrawing meso-substituents stabilize the LUMO energy, while electron-donating mesosubstituents destabilize the LUMO energy. ${ }^{34}$ Considering this, comparison of the asymmetric napthyl-pyrrole dyes (1-3) shows that the LUMO energy is destabilized in the dyes with the electron donating para-fluoro and para-methyl phenyl mesosubstituents compared to the meso-phenyl dye, Scheme 3. For the symmetric napthyl-pyrrole dyes (4-7), the LUMO energy exhibiting the greatest destabilization is associated with the meso-trimethoxyphenyl-substituted dye (4) while the most stabilized of this group belongs to the meso-thienyl substituted dye (6). The LUMO energy for the meso-substituted hydroxynaphthyl (5) and pyrene (7) dyes is identical. This is surprising because, in the case of the fluorantho-pyrrole dyes, the pyrene-substituted dye (9) shows greater LUMO destabilization compared to the hydroxy-naphthyl fluorantho dye (8). However, this difference in energy may be associated with the symmetry or lack of symmetry since the asymmetric dyes destabilize the LUMO energy more than the symmetric dyes.

\section{Conclusions}

A simple two-step synthetic route to new BODIPY dyes has been established for a variety of aromatic aldehydes and $\pi$-conjugated pyrroles. These dyes display significant photophysical properties that can be tuned by both the choice of aldehyde as well as the choice of $\pi$-conjugated pyrrole. The role of the aldehydes plays less of a role in tuning the photophysical properties. Nevertheless, the versatility displayed by these aldehydes may allow for structural adaptations which could prove advantages for numerous applications. It is clear that the greatest effect on the photophysical properties lies with the conjugation associated with the pyrroles. Extending this conjugation further may lead to efficient BODIPY dyes capable of light absorption and emission properties well into the nearIR region of the electromagnetic spectrum.

\section{Acknowledgements}

Time-resolved emission data was collected on an emission spectrophotometer (Edinburgh Instrument, FLS920) housed in the UNC EFRC Instrumentation Facility established by the UNC EFRC Center for Solar Fuels, an Energy Frontier Research Center funded by the U.S. Department of Energy, Office of Science, Office of Basic Energy Sciences under Award DE-SC0001011.

\section{Notes and references}

1 A. Loudet and K. Burgess, Chem. Rev., 2007, 107, 4891-4932. 2 A. Mishra, M. K. R. Fischer and P. Bauerle, Angew. Chem., Int. Ed., 2009, 48, 2474-2499.

3 G. Ulrich, R. Ziessel and A. Harriman, Angew. Chem., Int. Ed., 2008, 47, 1184-1201.

4 S. Kolemen, M. Isik, G. M. Kim, D. Kim, H. Geng, M. Buyuktemiz, T. Karatas, X.-F. Zhang, Y. Dede, J. Yoon and E. U. Akkaya, Angew. Chem., Int. Ed., 2015, 54, 53405344.

5 (a) A. Kamkaew, S. H. Lim, H. B. Lee, L. V. Kiew, L. Y. Chung and K. Burgess, Chem. Soc. Rev., 2013, 42, 77-88; (b) S. G. Awuah and Y. You, RSC Adv., 2012, 2, 11169-11183; (c) Z. Wang, X. Hong, S. Zong, C. Tang, Y. Cui and Q. Zeng, Sci. Rep., 2015, 5, 12602; (d) X. Hong, Z. Wang, J. Yang, Q. Zheng, S. Zong, Y. Sheng, D. Zhu, C. Tanga and Y. Cuic, Analyst, 2012, 137, 4140-4149.

6 T. Gayathri, A. K. Barui, S. Prashanthi, C. R. Patra and S. P. Singh, RSC Adv., 2014, 4, 47409-47413.

7 A. M. Courtis, S. A. Santos, Y. Guan, J. A. Hendricks, B. Ghosh, D. M. Szantai-Kris, S. A. Reis, J. V. Shah and R. Mazitschek, Bioconjugate Chem., 2014, 25, 1043-1051.

8 L. Yang, Y. Liu, W. Liu, C. Ma, C. Zhang and Y. Li, Bioorg. Med. Chem. Lett., 2015, 25, 5716-5719.

9 S. D. Topel, O. Topel, R. B. Bostancioglu and A. T. Koparal, Colloids Surf., B, 2015, 128, 245-253.

10 G. Fan, L. Yang and Z. Chen, Front. Chem. Sci. Eng., 2014, 8, 405-417.

11 B. Sui, S. Tang, T. Liu, B. Kim and K. D. Belfield, ACS Appl. Mater. Interfaces, 2014, 6, 18408-18412.

12 S. P. Singh and T. Gayathri, Eur. J. Org. Chem., 2014, 22, 4689-4707.

13 S. Debnath, S. Singh, A. Bedi, K. Krishnamoorthy and S. S. Zade, J. Phys. Chem. C, 2015, 119, 15859-15867.

14 S. Madhu and M. Ravikanth, Inorg. Chem., 2012, 51, 42854292.

15 T. Kowada, S. Yamaguchi and K. Ohe, Org. Lett., 2010, 12, 296-299.

16 C. Yu, L. Jiao, P. Zhang, Z. Feng, C. Cheng, Y. Wei, X. Mu and E. Hao, Org. Lett., 2014, 16, 3048-3051. 
17 C. Cheng, N. Gao, C. Yu, Z. Wang, J. Wang, E. Hao, Y. Wei, X. Mu, Y. Tian, C. Ran and L. Jiao, Org. Lett., 2015, 17, 278-281.

18 A. B. Descalzo, H.-J. Xu, Z.-L. Xue, K. Hoffmann, Z. Shen, M. G. Weller, X.-Z. You and K. Rurack, Org. Lett., 2008, 10, 1581-1584.

19 Y. Kubo, K. Watanabe, R. Nishiyabu, R. Hata, A. Murakami, T. Shoda and H. Ota, Org. Lett., 2011, 13, 4574-4577.

20 S. Yamazawa, M. Nakashima, Y. Suda, R. Nishiyabu and Y. Kubo, J. Org. Chem., 2016, 81, 1310-1315.

21 Y. Hayashi, N. Obata, M. Tamaru, S. Yamaguchi, Y. Matsuo, A. Saeki, S. Seki, Y. Kureishi, S. Saito, S. Yamaguchi and H. Shinokubo, Org. Lett., 2012, 14, 866-869.

22 L. Luo, D. Wu, W. Li, S. Zhang, Y. Ma, S. Yan and J. You, Org. Lett., 2014, 16, 6080-6083.

23 C. Maeda, T. Todaka and T. Ema, Org. Lett., 2015, 17, 30903093.

24 Z.-B. Sun, M. Guo and C.-H. Zhao,J. Org. Chem., 2015, 229-237.

25 Y.-W. Wang, A. B. Descalzo, Z. Shen, X.-Z. You and K. Rurack, Chem.-Eur. J., 2010, 16, 2887-2903.
26 S. Swavey, M. Coladipietro, A. Burbayea and J. A. Krause, Eur. J. Org. Chem., 2016, 4429-4435.

27 T. D. Lash, M. L. Thompson, T. M. Werner and J. D. Spence, Synlett, 2000, 2, 213-216.

28 T. D. Lash, T. M. Werner, M. L. Thompson and J. M. Manley, J. Org. Chem., 2001, 66, 3152-3159.

29 H. Sunahara, Y. rano, H. Kojima and T. Nagano, J. Am. Chem. Soc., 2007, 129, 5597-5605.

30 J. Banuelos, I. J. Arroyo-Cordoba, I. Valois-Escamilla, A. Alvarez-Hernandez, E. Pena-Cabrera, R. Hu, B. Z. Tang, I. Esnal, V. Martinez and I. L. Arbeloa, RSC Adv., 2011, 1, 677-684.

31 R. Ziessel, C. Goze, G. Ulrich, M. Cesario, P. Retailleau, A. Harriman and J. P. Rostron, Chem.-Eur. J., 2005, 11, 7366-7378.

32 LUMO $(\mathrm{eV})=-\left(E_{\text {red }}+4.8\right)$; HOMO $(\mathrm{eV})=-\left(E_{\mathrm{ox}}+4.8\right)$.

33 J. Banuelos Prieto, F. Lopez Arbeloa, V. Martinez Martinez and I. Lopez Arbeloa, Chem. Phys., 2004, 296, 13-22.

34 J. K. Petrushenko and K. B. Petrushenko, Spectrochim. Acta, Part A, 2015, 138, 623-627. 